\title{
Evaluation of oral Health-Related Knowledge And Practice Among Students of Secondary Education Schools in Durrës, Albania
}

\author{
Msc. Enxhi Hasani \\ (Student, Public Health Department, Faculty Of Medicine, University Of Medicine In Tirana, Albania)
}

\begin{abstract}
This study was conducted to investigate the oral health - related knowledge and practice among students of public secondary education schools in Durrës, Albania and to see if these practices were correlated with gender, parents' education years and parents' profession (dentist, health related or not health related profession).

A questionnaire study was conducted among 360 students in public schools of secondary education in Durrës. A self-administered questionnaire was used to obtain information about demographic characteristics of the respondents and their oral health - related knowledge and practices. A descriptive analysis followed by a correlation analysis was conducted using the Statistical Package for the Social Sciences (SPSS) version 20.

The majority of respondents (61.1\%) brushed their teeth twice a day, while a lot did not know what dental floss (27.2\%) and mouthwash (46.1\%) were. $64.2 \%$ changed their toothbrush after 3 months of use. Most of them (41.7\%) went to the doctor only when in pain and only $37.5 \%$ went every six months. The main source of information was considered the dentist. Generally, females had better practices and knowledge than males. Having one parent whose profession was related to health care did not make them have a better oral health care routine.

The oral health - related knowledge and practices are moderate and a lot should be done to improve it. A good informative strategy is needed since oral health is important and impacts general health.
\end{abstract}

Keywords: oral health, oral hygiene practice, secondary education school, Durrës, Albania.

\section{Background}

Oral health is essential to general health and quality of life according to the WHO and teeth are a part of it [1]. For a proper oral hygiene routine, these recommendations should be followed [2]: brushing after each meal or at least twice a day, using a pea-sized dab of toothpaste on the head of a soft toothbrush. While cleaning teeth, circular motions should be used, and the process should last between 2 to 3 minutes. It is recommended to clean teeth after eating, but to wait at least 30 minutes in order to not harm the teeth enamel. Also, the toothbrush should be replaced three to four months after being used. It is also important to floss teeth and rinse mouth at least once a day, avoid sugary foods and go to the dentist once every six months.

Proper dental health still remains a problem in many countries The WHO has estimated that worldwide $60-90 \%$ of school children and nearly $100 \%$ of adults have dental cavities [1].

In Albania, there have been some studies evaluating dental health situation. In some of them is used the DMFT index (Decayed, Missing, Filled Permanent teeth) for adults and the dmft index (decayed, missing, filled in deciduous teeth) for children.

In a study conducted on schools in Tirana during the academic year $2009-2010$ it was estimated that the total dmft index (decayed, missing and filled teeth in deciduous dentition) was 2.082; dmft in males was 2.137, in females was 2.032, while the total DMFT index (Decayed, Missing and Filled Teeth in permanent dentition) was 2.327; DMFT in males was 2.253, in females was 2.396. Decayed teeth were the principal component of both dmft and the DMFT index. Caries prevalence resulted higher in girls than boys in deciduous and in permanent teeth [3].

A cross - sectional survey of the year 2011 was also conducted among 12 years old children in Albania including 1928 children from public schools across 16 local districts with a mix of urban and rural areas and contrasting socio-economic groups. It concluded that the caries prevalence (DMFT > 0) was $87 \%$ and the DMFT index was 3.73 for boys, 3.71 for girls and 3.72 overall [4].

After Tirana, the capital, Durrës is the city with the largest population density according to the Census of 2011 [5]. Both cities are the most financially developed area of the country and are similar to each other, which make it possible to evaluate with this study the oral health - related knowledge and practices among the most developed part of Albania. According to a study conducted in Durres County in 2013, the dmft for 7, 8, 9, 10 years old children was respectively $3.7 ; 4.3 ; 3.6$ and 2.1 while the caries prevalence was $92.1 \%$ [6].

Since most of the studies conducted were about the DMFT or dmft index or about caries prevalence, this study was conducted with the aim of investigating the oral health - related knowledge and practices among 
students of secondary education schools in Durrës, Albania and to see if these practices were correlated with gender, parents' education years and parents' profession (dentist, health related or not health related profession).

\section{Methods}

A cross - sectional study was conducted to collect information about oral health knowledge and practices from a sample of 360 students of public schools of secondary education in Durrës.

From all secondary education schools, only public schools were selected and only those with regular and not professional education were selected. From each of the three schools included, were randomly selected 40 students from the first, 40 from the second and 40 from the third year to be part of the study. Oral consent was taken.

A self-administered questionnaire with close - ended questions was used. These questions obtained basic socio - demographic information like age, gender, parents' education and profession and also specific information about the respondents' teeth cleaning routine and care and their visit to the dentist. Questions to assess the general knowledge of the students related to the topic were also included. The respondents were instructed to fill the questionnaire without discussion with each other in their own classroom. They took about 15 minutes to complete the questionnaire.

For the statistical analysis was used the Statistical Package for the Social Sciences (SPSS) version 20. A descriptive analysis was conducted to show the frequencies of the behaviors of the respondents, as well as a correlation analysis was conducted to see if these behaviors were related to the gender of the students, or their parents years of education or profession (dentist, or health related profession or not health related profession). Kendall tau $b$ was used to correlate nominal variables and the significance level was $p \leq 0.01$.

\section{Results}

All the 360 students invited to participate in the study did so (209 or $58 \%$ were females and 151 or $42 \%$ were males). So the response rate was $100 \%$. The sample had people aged from 14 to 20 years old, with most of them (37.2\%) aged 17 years old, and least of them 20 and 19 years old (respectively 2 and 5 participants only). More than half $(57.5 \%)$ of the participants reported that at least of their parents had finished University while only $2 \%$ of them said that they had at least one parent with less than 8 years of education. Also, $92.8 \%$ of the participant had parents whose profession had nothing to do with healthcare while only 2 of the 360 students $(0.6 \%)$ interviewed had a dentist parent and the remaining $6.6 \%$ had at least one parent whose profession was related to healthcare but was not a dentist.

Table 1: Frequency of teeth cleaning

\begin{tabular}{|c|c|c|c|}
\hline Not everyday & Once a day & $\begin{array}{c}\text { Twice a day (morning and } \\
\text { before sleeping) }\end{array}$ & After each meal \\
\hline $1.9 \%$ & $22.5 \%$ & $61.1 \%$ & $14.4 \%$ \\
\hline
\end{tabular}

About their teeth care routine, as shown in table 1,1.9\% didn't clean their teeth every day, while most of them $(61.1 \%)$ cleaned their teeth twice a day, with the remaining $14.4 \%$ who did so after each meal and $22.5 \%$ only once a day. $83 \%$ cleaned their teeth after eating, of which only $38.6 \%$ of them waited at least 30 minutes and $61.4 \%$ cleaned them immediately; while $17 \%$ cleaned their teeth before eating. Half of the participants (50\%) used soft circular motions while cleaning their teeth and the other $50 \%$ used harsh motions.

As shown in table 2, only $64.2 \%$ changed their toothbrush after 3 months of use, $24.9 \%$ after 6 months of use while $6.4 \%$ continued to use the same toothbrush until it could not be used anymore. The procedure of teeth cleaning lasted about 2 to 3 minutes for $34.1 \%$ of the students only while for the remaining $65.9 \%$ of them it lasted less than this time. $87.3 \%$ used chewing gum when they could not clean their teeth outside their house.

Table 2: Toothbrush change frequency

\begin{tabular}{|c|c|}
\hline Toothbrush change frequency & Percentage \\
\hline Use the same toothbrush until it can be used & $6.4 \%$ \\
\hline Change the toothbrush after using it for 6 months & $29.4 \%$ \\
\hline Change the toothbrush after using it for 3 months & $64.2 \%$ \\
\hline Total & $100.0 \%$ \\
\hline
\end{tabular}

As shown in table $3,27.2 \%$ of the students had never heard of dental floss, and among those who did know what is was, only $8.6 \%$ used it once a day; $5 \%$ used it twice a day and $38.3 \%$ used it randomly, while the remaining $20.8 \%$ never used it. 
Table 3: Dental floss use frequency

\begin{tabular}{|c|c|}
\hline \multicolumn{2}{|c|}{ Percentage } \\
\hline Never uses dental floss & $20.8 \%$ \\
\hline Use it randomly, only sometimes & $38.3 \%$ \\
\hline Use it once a day & $8.6 \%$ \\
\hline Use it twice a day & $5.0 \%$ \\
\hline Dotal & $27.2 \%$ \\
\hline
\end{tabular}

$46.4 \%$ of the students did not know what mouthwash was while among those who knew, $5.8 \%$ did not rinse their mouth at all, and $18.1 \%$ did it once a day; $8.6 \%$ twice a day and 21.1 only rinsed their mouth randomly.

Table 4: How frequently students rinse their mouth

\begin{tabular}{|c|c|}
\hline \multicolumn{2}{|c|}{ Percentage } \\
\hline The student knows that mouthwash is but does not use it & $5.8 \%$ \\
\hline Randomly, not always rinses mouth & $21.4 \%$ \\
\hline Rinses mouth once a day & $18.1 \%$ \\
\hline Rinses mouth twice a day & $8.6 \%$ \\
\hline The student did not know what mouthwash is & $46.1 \%$ \\
\hline Total & $100.0 \%$ \\
\hline
\end{tabular}

$23.6 \%$ of the students ate sugary foods more than once a day. About the visit to the dentist, only $37.5 \%$ went once every six months and $41.7 \%$ went only when they felt pain, while $20.8 \%$ went once a year. Also, $28.9 \%$ of the students did not seek immediate care when they had strong pain but waited to see if the pain would go away on its own without any help. $40 \%$ did not know exactly what dental caries is or what causes it and if it is infectious or not. $90 \%$ were optimistic and said that they believed they had a good oral hygiene routine. The main sources of information related to teeth care were the dentists, family members, school, and media (respectively for 35\%, 30\%, 13\% and $12 \%$ of students). 10\% declared nobody had ever informed them.

For the correlation analysis, only a few of them resulted significant with p less than 0.01 and most of the correlations were weak.

A correlation was found between gender and frequency of teeth cleaning (value of the correlation coefficient was 0.167 ). Among those with the worst practices, so those who did not clean their teeth every day, $57.1 \%$ were males and among those who cleaned their teeth only once a day, $56.8 \%$ were males. While among those with a better oral health practice: among those who cleaned teeth twice a day, $61.4 \%$ were females and those who cleaned teeth after each meal, $69.2 \%$ were females.

Table 5: Frequency of teeth cleaning and gender correlation

\begin{tabular}{|c|c|c|c|c|}
\hline Gender & Not everyday & Once a day & $\begin{array}{c}\text { Twice a day (morning and } \\
\text { before sleeping) }\end{array}$ & After each meal \\
\hline Female & $42.9 \%$ & $43.2 \%$ & $61.4 \%$ & $69.2 \%$ \\
\hline Male & $57.1 \%$ & $56.8 \%$ & $38.6 \%$ & $30.8 \%$ \\
\hline TOTAL & $100 \%$ & $100 \%$ & $100 \%$ & $100 \%$ \\
\hline
\end{tabular}

A weak correlation was also found between gender and frequency of toothbrush change (correlation coefficient 0.136). Among those who change the toothbrush after using it for 3 months, 51.9\% were females, while among those who would use the same toothbrush until it could not be used anymore, $56.5 \%$ were males. The remaining group, those who changed their toothbrush after 6 months of use, $74.5 \%$ were females.

$48 \%$ of males and $30 \%$ of females did not know exactly what dental caries is. The correlation coefficient between gender and this knowledge was 0.230 .

A weak correlation with a coefficient of 0.148 was also found between the parent profession (if the parent was a dentist, had a profession linked to health care or a profession that had nothing to do with healthcare) and the floss use. As shown in the table $100 \%$ of those with one parent who is a dentist use it only sometimes. Most of those with a parent who had a health related profession did not even know what a dental floss is (42\%), while among those whose parent's profession had nothing to do with healthcare $26 \%$ did not know what dental floss is, most of them, $40 \%$ used it sometimes and $12 \%$ use it least once (8\% once and $4 \%$ twice a day). 
Table 6: Use of dental floss and parents profession correlation

\begin{tabular}{|c|c|c|c|c|c|c|}
\hline Parents Profession & $\begin{array}{l}\text { The student does } \\
\text { not know what a } \\
\text { dental floss is }\end{array}$ & $\begin{array}{l}\text { Never } \\
\text { uses it }\end{array}$ & $\begin{array}{c}\text { Uses it } \\
\text { sometimes but } \\
\text { not always } \\
\text { (random use) } \\
\end{array}$ & $\begin{array}{c}\text { Uses it once a } \\
\text { day }\end{array}$ & $\begin{array}{c}\text { Uses it twice a } \\
\text { day }\end{array}$ & TOTAL \\
\hline $\begin{array}{c}\text { One of the parents is } \\
\text { a dentist }\end{array}$ & $0 \%$ & $0 \%$ & $100 \%$ & $0 \%$ & $0 \%$ & $100 \%$ \\
\hline $\begin{array}{c}\text { One of the parents is } \\
\text { not a dentist but has a } \\
\text { profession related to } \\
\text { health care }\end{array}$ & $42 \%$ & $8 \%$ & $8 \%$ & $17 \%$ & $25 \%$ & $100 \%$ \\
\hline $\begin{array}{l}\text { None of the parents } \\
\text { has a profession } \\
\text { linked to health care }\end{array}$ & $26 \%$ & $22 \%$ & $40 \%$ & $8 \%$ & $4 \%$ & $100 \%$ \\
\hline
\end{tabular}

\section{Discussion}

Oral hygiene is fundamental to the maintenance of oral health; therefore oral hygiene knowledge and practices were the main concern of this study. To obtain this information a self-administered questionnaire with close - ended questions was used. The questionnaire was structured in order to contain all basic information that has to do with proper teeth hygiene. In order to obtain genuine responses, the anonymity of the respondents was ensured. Based on the results of this study it is not yet implemented a proper oral health care and teeth hygiene culture among young people (in this case aged between 14 and 20 years old).

$61.1 \%$ were the respondents who cleaned their teeth twice a day and there are yet people who did not clean teeth every day, in this case, $1.9 \%$. There were also respondents who used the same toothbrush for more that it should be used, so $6.4 \%$ would use it until it could be used, while only $64.2 \%$ followed the proper recommendation to use the same toothbrush for 3 months only. More than half (83\%) cleaned teeth after eating which is good to prevent cavities, but only $38 \%$ of them waited at least 30 minutes after eating, which means they can damage their teeth enamel. Add to it the fact that also $50 \%$ of the respondents used harsh motion instead of soft circular motions while cleaning teeth. Apparently, according to the results, most students in Durrës stick to brushing only, since some did not even know what dental floss (27.2\%) and mouthwash (46.1\%) were.

Less than half (37.5\%) followed the health recommendation of going to the dentist every 6 months and the majority (41.7\%) went only when in pain. This is bad because most preventable or reversible conditions are left untreated which make them seek attention for more serious needs. Even in pain, 28.9\% did not seek attention immediately but waited if it passed without the need of a dentist. This can be due to the fact that in Albania most people prefer to go to the private sector instead of the public sector. Another factor could be the fear which is high in case of dental problems.

In general, the students did not have a lot of oral health information. Mention here those who did not know what dental floss and mouth rinsing meant, but also that $40 \%$ of the respondents did not know what dental caries is or what caused it. $10 \%$ of them even claimed that nobody had ever informed them, while for the others the most important sources of information were the dentist, family members, school and media. This information may help institutions like The Institute of Public Health in Albania so they can choose the best information provider for oral health practice. In fact, it would be a good idea to start considering an informative strategy to improve teeth hygiene since most respondents did not have quite a good knowledge and attitude.

In this study was conducted a correlative analysis but most of the results were not significant and among those that resulted significant, the correlations were weak in general with not a lot of differences between groups. Between genders, females had a slightly better oral health care practice and knowledge. While for the correlations with the parents' jobs, it was expected that children whose one of the parents was a dentist, would have a better teeth hygiene. But as we can see from the results, $100 \%$ of them used dental floss randomly, while among those whose parents' job was not health care related $4 \%$ used dental floss twice a day and $8 \%$ once a day. $17 \%$ used it once a day and $20 \%$ twice a day among those whose at least one parent had a job related to health care but not a dentist. However, conclusions about this are not too reliable since from the students who were interviewed, most of them (92.8\%) had parents whose profession was not health care related and only $7.2 \%$ had at least one parent related to healthcare (of which $0.6 \%$ had a dentist parent and $6.6 \%$ other).

This study was conducted in Durrës which is after Tirana the city with the highest population density and also both cities are the most financially developed ones in Albania. This means that the oral health - related knowledge and practices were evaluated among the population with better economic status. It is normally expected that if there is better economic status, even lifestyle would be healthier. This means that probably these practices are even poorer in other cities of Albania. Anyway, this is just a suggestion and further studies should be done to evaluate it. 


\section{Conclusions}

Oral health is essential to general health and quality of life according to the WHO and teeth are part of it. The aim of this study was to investigate the oral health - related knowledge and practices among students of secondary education schools in Durrës, Albania and to see if these practices were correlated with gender, parents' education years and parents' profession (dentist, health related or not health related profession). The oral health knowledge and practices among secondary education schools in Durrës, Albania is moderate. Further studies should be conducted to evaluate these practices in other areas of Albania to see if they are even worse, since being Durrës financially developed and having these results, it is expected that the situation could be even worse in other cities. All the information obtained from this study and other studies that can be done in the future can be used in planning proper informative strategies to improve the oral health - related knowledge and practices and encourage people to take better care of their teeth hygiene.

\section{References}

[1]. "WHO | Oral health," WHO. [Online]. Available: http://www.who.int/mediacentre/factsheets/fs318/en/. [Accessed: 06-Mar-2017].

[2]. "Teeth And Gum Care," WebMD. [Online]. Available: http://www.webmd.com/oral-health/teeth-and-gum-care. [Accessed: 06Mar-2017].

[3]. G. Laganà et al., "Caries prevalence in a 7- to 15-year-old Albanian schoolchildren population,” Ann. Stomatol. (Roma), vol. 3, no. 2, pp. 38-43, Aug. 2012.

[4]. D. Hysi, E. Droboniku, and C. Toti, "Caries experience and treatment needs among Albanian 12-year-olds," Community Dent. Health, vol. 31, no. 3, pp. 141-144, Sep. 2014.

[5]. INSTAT Albania, "Population and Housing Census 2011." Adel Print, 2012.

[6]. M. Fiorda, "The progress of dental caries in the mixed dentition of 7-10-year-old children in Durres district, Albania," Med. Rev. E Shoq. Së Mjekëve Shqip. Në Maqedoni, vol. 18, no. 1, pp. 49-54, 2013. 